And I would here emphasize the fact that casts are very common in diabetic coma. This phenomenon, to which attention was first called by the late E. Külz, and which has been confirmed by Aldehoff," Williamson and others, is worthy of note for two reasons. 1. It may give warning of the approach of coma, being occasionally seen even in the prodromal stage. Kiilz described such cases and Williamson has seen the same thing occur. I have seen casts in the urine in four cases of diabetic coma, in fact in all the cases of this form of coma I have seen since my attention was first called to Külz's phenomenon by reading Williamson's book. ${ }^{6}$ In one case, that of a man about 60 , the urine on standing showed a light yellowish or grayish sediment that consisted of an enormous number of the typical short, finely granular "coma-casts," as Aldehoff calls them. There were as many casts in a field as I have ever seen in any nephritic urine. There was but a trace of albumin. A few weeks ago the urine of a woman with diabetes revealed no casts in the centrifugalized specimen. Two days later coma began and casts were abundant. 2. A knowledge of the occurrence of casts in the urine of diabetic coma will enable the physician to avoid mistaking this form of coma for uremia, because of the albumin and casts.

On examining the urine it may be found of low specific gravity and on this account the examination for sugar may be deemed unnecessary. 'This is a grave error. The sugar-containing urine of diabetes may be of low specific gravity from a variety of causes. Strümpell says that it may be low when there is pronounced debility. The development of chronic interstitial nephritis will lower the specific gravity and might offer an explanation for the increased amount of urine and the thirst, as well as for other symptoms. In the latter part of April of this year I examined a man of 54, a diabetic, which diagnosis had been made two years before. He had a consolidated left apex. The total urine for twenty-four hours was 1500 c.c., it contained a moderate trace of albumin, casts, a small amount of sugar. Its specific gravity was but 1012. Another cause for low specific gravity is the drinking of large amounts of fluids. A patient of mine drinking large amounts of some spring water kept the specific gravity between 1015 and 1019. yet there was always sugar in the urine. Another patient after drinking beer all the morning passed urine with a specific gravity of 1004 and yet containing abundance of sugar. Cases with a specific gravity as low as 1002 are reported. And in the series of cases of Külz, many times records of 1010 or under were made. The importance, therefore, of examining for sugar even when the specific gravity is low is clearly seen, and the rules of some of our life insurance companies requiring such examination only when the specific gravity is above 1015 or 1020 need radical revision.

There may be no sugar in the urine at the time of examination.

At times a prediabetic or prodromal polyuria is seen without glycosuria; and as the sugar disappears in cases of permanent or temporary recovery there may be a non-saccharine polyuria.

When chronic interstitial nephritis occurs sugar may diminish, or even entirely disappar.

Acute infectious diseases, as pneumonia, influenza, typhoid fever, frequently cause a temporary disappearance of the sugar. These infectious diseases are often wrongly assigned as the cause of diabetes. For if a

5. Külz's Klinische Erfahrungen über Diabetes, 1899 .

6. Ierrick: Notes on Diabetes, Amer, Jour. Med. Science, July, 1900 . patient with pneumonia shows no sugar in the urine and a week after defervescence sugar appears and remains, one could readily reach the conclusion that the pneumonia was the exciting cause of the glycosuria, when in reality exactly the opposite is the fact; the sugar formerly present has disappeared under the influence of the acute infection only to reappear later.

The glycosuria in some of the milder forms of diabetes may be periodic or cyclic, reminding one of the cyclic albuminurias. An examination at a sugar-free period would therefore lead one to a false conclusion, unless subsequent control examinations were made, and especially examinations following a known diet of carbohydrates-similar to the test for alimentary glycosuria.

In conclusion, I would call attention to the importance not only of diagnosing the diabetes, but of recognizing the variety of the disease. While the classifications are all more or less artificial, they are yet valuable, and if we make no sharper distinction than between mild, moderately severe and severe types, our treatment will be far more rational and effectual and our prognosis far nearer the truth than if we make merely one large class including all cases of diabetes. Due consideration of the age, tendency to obesity, heredity and of organic disease of the pancreas or nervous system as an etiologic factor cnables one to recognize the type. And of especial value is it to note the effect of withdrawal of carbohydrates. In many of the milder types, particularly in the obese adult, the sugar can be made quickly to disappear from the urine by proper diet, while in severer forms, in soite of most rigid diet, sugar persists. It is not always the amount of sugar that determines the severity of a given ease; it is rather the amount in comparison with thr amount of carbohydrates in the diet.

\section{I)IABFTES MELIITUS.}

TILE MORTALITY THEREFROA IN THE CITY OF NEW YORK DURLNG THE PERTOD FROM 1889 TILL 1899; FROM THE OFFICIAL RECORDS. COMMENTS.*

HEIXRICH STERX. PH.D.. M.1).

NEW YORK CITY.

It is an exceptional occurrence that the mortality statistics of diabetes mellitus are closely studied. This has been especially the case with the pertinent statistic material of American communities. The principal cause for this omission lies undoubtedly in the supposed rare appearance of the affection. It is possible that diabetes in bygone years, before the strong current of immigration had set in, was of less frequency on this continent and that the proportion of deaths following this condition was smaller than it is to-day: but it is also possible that the American practitioner of some generations ago did not recognize the disease as readily as we modern Esculapians do.

The mortality statistics of the American metropolis in regard to diabetes mellitus, heretofore, were hardly ever thoroughly revised and studied. I am greatly indebted to Dr. Roger S. Tracy, one of the eminent statisticians of this country and the registrar of the New York Board of Health, for the assistance he so generously has lent me in the compilation of the statistic material and for the privilege of granting me access to the original documents. This communication treats only of a portion of the relevant matter-the elaboration of

* Presented to the Section on Practice of Medicine, at the Fifty-first Annual Meeting of the American Medical Association, held at Atlantic City, N. J.. June 5-8, 1900. 
other statistics, especially those for the year 1899, I have reserved for another communication. ${ }^{1}$

TOTAL MORTALITY FROM DIABETES MELLITUS.

\begin{tabular}{|c|c|c|c|c|}
\hline & Year. & Males. & Females.| & $\begin{array}{c}\text { Total } \\
\text { number. }\end{array}$ \\
\hline 1889 & $\ldots \ldots \ldots \ldots \ldots \ldots \ldots$ & 71 & 47 & 118 \\
\hline 1890 & $\ldots \ldots \ldots \ldots \ldots \ldots \ldots$ & 72 & 58 & 130 \\
\hline 1891 & $\ldots \ldots \ldots \ldots \ldots \ldots \ldots$ & 64 & 66 & 130 \\
\hline 1892 & $\ldots \ldots \ldots \ldots \ldots \ldots \ldots$ & 66 & 57 & 123 \\
\hline 1893 & $\ldots \ldots \ldots \ldots \ldots \ldots \ldots$ & ;6 & 61 & 137 \\
\hline 1894 & $\ldots \ldots \ldots \ldots \ldots \ldots \ldots$ & 87 & 79 & 166 \\
\hline 1895 & $\cdots \ldots$ & 95 & 108 & 203 \\
\hline 1896 & $\ldots \ldots \ldots \ldots \ldots \ldots \ldots \ldots$ & 98 & 116 & 214 \\
\hline 1897 & $\ldots \ldots \ldots \ldots \ldots \ldots \ldots \ldots$ & 95 & 107 & 202 \\
\hline 1898 & $\ldots \ldots \ldots \ldots \ldots \ldots \ldots \ldots$ & 108 & 130 & 238 \\
\hline 1899 & $\cdots$ & 104 & 102 & 206 \\
\hline Tot & al in years ......... & 936 & 931 & 1867 \\
\hline
\end{tabular}

Of 1867 deaths from diabetes mellitus, 931, that is, almost 50 per cent. occurred in females. This proportion differs widely from the supposition that the affection is much more fatal in males than in females. Former mortality reports have shown that from two to two and a half times more men succumbed to this malady than women. That in both sexes the death frequency from diabetes mellitus should be so equally proportioned may be partially attributed to the struggle for existence from which the modern woman is no longer exempt. Moreover, it is but consequential to assume that the deathrate from diabetes mellitus stands in direct proportion to the frequency of the disease itself, and that in New Iork City about equal numbers of both sexes are afflicted with it.

The following table gives the population of New York City-Manhattan and Bronx-estimated for July 1, in each year, total deaths, total death-rate per 1000 of the population, death-rate from diabetes mellitus per 1000 of population, and deaths from diabetes per 1000 deaths, from 1889 till 1899, inclusive.

\begin{tabular}{|c|c|c|c|c|c|}
\hline Year. & Population & $\begin{array}{l}\text { Total } \\
\text { deaths. }\end{array}$ & $\begin{array}{c}\text { Total } \\
\text { death- } \\
\text { rateper } \\
1000 .\end{array}$ & $\begin{array}{l}\text { Death-rate } \\
\text { from D. M. } \\
\text { per } 1000 \\
\text { population }\end{array}$ & $\begin{array}{c}\text { Deaths } \\
\text { from } D . M . \\
\text { per } 1000 \\
\text { deaths. }\end{array}$ \\
\hline$\overline{\mathrm{1889}}$ & $1,566,801$ & 39,679 & 25.32 & 0.07 & $2, \overline{95}$ \\
\hline 1890 & $1,612,559$ & 40,103 & 24.87 & 0.08 & 3.25 \\
\hline 1891 & $1,659,654$ & 43,659 & 26.31 & 0.08 & 2.95 \\
\hline 1892 & $1,708,124$ & 44,329 & 25.95 & 0.07 & 2.8 \\
\hline 1893 & $1,758,010$ & 44,486 & 25.30 & 0.08 & 3.11 \\
\hline 1894 & $1,809,353$ & 41,175 & 22.76 & 0.09 & 4.05 \\
\hline 1895 & $1,879,195$ & 43,420 & 23.11 & 0.11 & 4.72 \\
\hline 1896 & $1,934,077$ & 41,622 & 21.62 & 0.11 & 5.09 \\
\hline 1897 & $1,990,562$ & 38,879 & 19.53 & 0.10 & 5.18 \\
\hline 1898 & 2.04 & 40,438 & 19.73 & 0.11 & 5.95 \\
\hline 1899 & $2,117,106$ & 39,911 & 18.85 & 0.09 & 5.15 \\
\hline
\end{tabular}

The death-rate from diabetes mellitus varied for the different years between $0.0 \%$ and 0.11 for each 1000 of the population. In the influenza year--1889 till 1890-. the mortality from diabetes mellitus per 1000 of the population amounted to but 0.8 -that is, the second lowest figure in the table. It is a remarkable fact that while the total death-rate has been in a rapid decline25.32 per 1000 population in 1889 , to 18.85 per 1000 population in 1899 - the mortality-rate from diabetes mellitus per 1000 population has been on the increase since 1894.

1. Meanwhile this article has appeared in the Medical Record on Nov. 17, 1900, under the title: "The Mortality from Diabetes Mellitus in the City of New York (Manhattan and The Bronx), in 1899." Classified according to month, sex, and age ; also an expose as to nationality, duration of residence in the United States, occupation, direct causes of death and accompanying diseases.
The deaths from the affection per 1000 total deaths were from the minimum 2.8 , in 1892 , to the maximum 5.95 , in 1898 .

While the increase in the death-rate from diabetes nellitus per 1000 of the population during the past six rear-1894 till 1899 -inclusive, is plainly noticeable, the increase of deaths attributed to diabetes mellitus per 1000 total deaths is still more striking. From 1889 till 1893, inclusive, the average mortality from this disrase per 1000 reported deaths amounted to 3.01 ; for the following six years, 1894 till 1899, inclusive, the proportion rose to 5.02 , an increase of 66 per cent.

On the other hand, the increase of the death-rate from rliabetes mellitus per 1000 of population, from 0.076 , the average of the Iustrum 1889-93 to 0.1 , the mean of the past six years, amounts to but 25 per cent.

While the death-rate from diabetes mellitus per 1000 of the population for the period of 1894-99 is larger by 25 per cent. than that of the five preceding years, the deaths from diabetes mellitus per 1000 reported deaths had increased 66 per cent. for the sime periods, or in other words, notwithstanding an absolute and relative increase, the latter in its proportion to 1000 inhabitants. the greater frequency of the fatal termination of diabetes compared with the total mortality is mainly due to the better and more general recognition of the disease. Formerly uranalysis was performed by but comparatively few physicians, and the true nature of the affection was not always recognized, and death, in many instances, was ascribed to other diseases than diabetes.

MORTALIT: FROA DIABETES MELLITUS ACCORDING TO ILONTII AND SEX-1889-99.

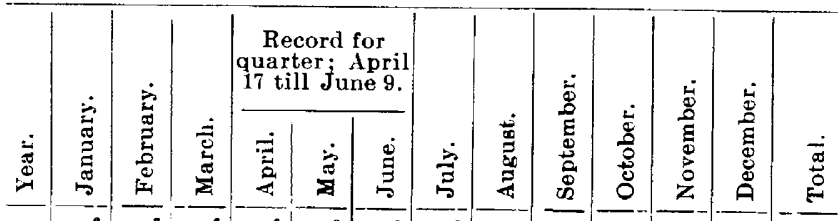

m. f. m. f. m. f.m. f.m.f.m. f. m. f. m. f.m.f. m. f. m. f. m. f.

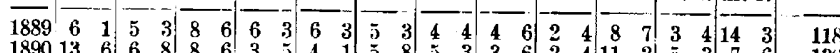

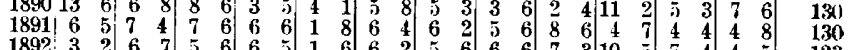

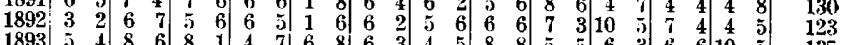

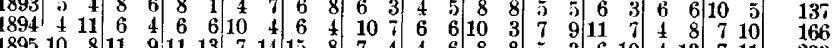

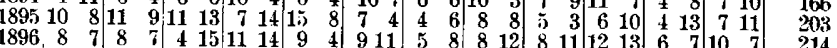

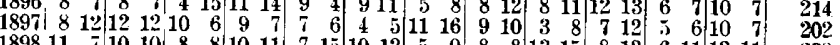

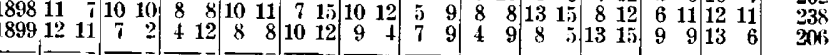

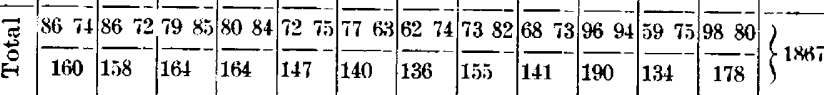

An examination of the foregoing table reveals the notable fact llat the month in which the most deaths from diabetes occurred is October, while the one in which the mortality from this disease was lowest is the month just following, November. The total mortality from diabetes for the veriod of 11 years for each month fluctuates between the two extremes, 190 deaths in October and 134 in November. It is remarkable how little the figures for certain months deviate from each other. Fatal terminations of the affection were recorded: January, 160; February. 158; March, 164; April, 164; Mav, 147 ; June, 140; July, 136; August, 155; September, 141: November, 134." In October and December the mortality from diabetes was somewhat greater, 190 and 178 , respectively.

Classing the months into seasons, the following figures are obtained: 
Spring: March, April and

May $\ldots \ldots \ldots \ldots \ldots \ldots 45$ deaths, or about 25 per cent. Summer: June, July and

August .........431 deaths, or about 23 per cent. Fall: September, October

and November .......465 deaths, or about 25 per cent. Winter: December, January

and February .......496 deaths, or about 27 per cent.

Total ......... $\quad \overline{1867}$ deaths, 100 per cent.

It is a noteworthy occurrence how almost uniformly the 1867 deaths were distributed over the different seasons. For a period of 11 years the total spring and fall mortality differed from each other but 10 deaths. The divergency between spring and fall mortality on the one side and the summer mortality on the other is somewhat greater, amounting, respectively, to 44 and 34 deaths in 11 years. The greatest divergency is found between summer and winter mortality, namely, 65 deaths in the period in question, or between 3 and 4 per cent.

Considering this last feature evolved by the statistics, it seems rather dubious whether temperature, sunshine, moisture, etc., as assumed by many authors, play any rôle whatsoever in the fatal termination of diabetes.

It could be surmised that the somewhat greater October mortality might be called forth by climatic occurrences; the validity of this assumption, however, is very questionable, as in the following month, November, when the climate does not differ materially from that of the preceding month, the mortality from diabetes was the lowest. The larger figure for October, in my opinion, is solely due to the fact that New York City is more populated during October than during any other month of the year. The people have then just returned from their summer sojourn in the country or abroad, and the exodus to southern regions has not yet begun. Many diabetics who have left the city during the summer months are among those who return and the mortality is somewhat increased simply by their presence in greater numbers.

The somewhat lessened mortality from diabetes during summer may be explained in a similar manner; a large percentage of the diabetics have bidden farewell to the sweltering city.

The mortality was greater in the male sex in January, February, June, October and December. The numebr of females who succumbed to diabetes was larger than that of the males in March, April, May, July, August, September and November.

MORTALITY FROM DIABETES MELLITUS aCCORDING TO AGE.

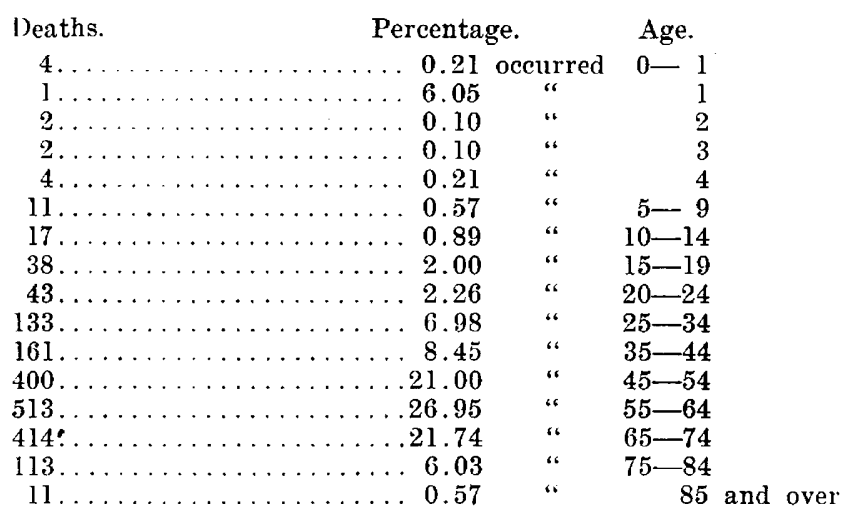

The greatest mortality from diabetes was found to be between 55 and 64 years of age. From the 65 th to the it th year the mortality declined about 20 per cent. and was about the same as between the 45th and 54 th years. Apart from the deaths under 1 year of age the mortality of diabetes increased to the period between the 55th and $6+$ th years, after which it slowly decreased to the 74 th year. A decline of about 70 per cent. in deaths from diabetes is noticed between the 75 th and 84 th years of age.

An abrupt rise of mortality is noted after the end of the 44 th year. While but 161 deaths were recorded for the period between the 35 th and 44 th years, an even 400 occurred between 45 and 54 years of age. Over 70 per cent. of all deaths took place between the 45th and 74th years of age. The fact that but 11 instances are recorded where the patient has lived to the 85th year and above, tends to show that only a very small percentage of diabeties reach an exceptionally high age.

Moreover it must not be construed as if the individual who succumbed to diabetes in an advanced age was necessarily afflicted with the disease for a long period. It ap. pears, on the contrary that the diabetic condition may be established late in life and that diabetes then acquired runs as rapid a course as in the very young.

From the 20 th to the 24th year the mortality from diabetes in the male sex is almost three times as large as in the female. Between the 25th and the 34th year the male mortalty was found to be about 30 per cent. larger. From the 35th to the 44th year the mortality of the male exceeded by about 18 per cent. that of the female. In the period between 45 and 54 years, the mortality of both sexes was almost analogous, and in that between the 55th and 64 th year the female mortality surpassed by a fair margin that of the male sex. In the next period, from the 65 th to the 74th year, the female mortality was also greater than that of the male, and in the period following, from the 75th to the 84th year, the female mortality was almost twice that of the male. In the period above 85 years the male mortality exceeded 4.5 times that of the other sex.

Exposure, excesses of a different nature, mental and bodily strain and worry undoubtedly stand in a causative relationship to the more frequent occurrence of diabetes and the subsequent greater mortality of the male from this affection between the 20th and 44th years of life. From the 45th to the 74th year the external conditions of life of both sexes are more alike and we notice a relative decrease in the mortality of the male, although the absolute figures are highest during this period.

The cessation of the catamenia, which takes place in many instances after the 44th year has been passed, and in the wake of which occurrence grave systemic disturbances not infrequently make their appearance, undoubtedly helps to swell the female mortality from diabetes between the 45 th and 48 th year.

The very high mortality of females after the 55th year and before the 84th year is reached, does not seem to be caused by any especial factor or factors, but seems rather due to the better care a woman can very often bestow upon herself.

If we add together the figures from the 20th to the 84 th year we find that for this period of life 884 deaths of males and 893 deaths of females from diabetes had ensued. These total figures are almost alike.

\section{MORTALITY FROM DIABETES MELLITUS IN INFANCY AND} EARLY ADOLESCENCE, 1889-99.

Judging by the mortality from diabetes mellitus in childhood, the period when this disease almost always terminates fatally, we may adduce that this malady is a rare affection in infancy and early adolescence. I found t cases of death from diabetes mellitus in infants below 1 year of age, during the 11 years from $1889-99$; at 1 year of age. 1 death: at 2 years, 2 deaths: at 3 vears, 2 
deuths; at 4 years, 4 deaths ensued, that is 13 instances in which the disease terminated fatally below the 5th year of life. Between the 5 th and 9 th year 11 cases of death are on record for the period in question; from the 10th to the 14 th year of life, I came across 17 recorded instances; and from the 15th to the close of the 19th year, the mortality from this affection amounted to 38 . The total mortality from diabetes in infancy and early adolescence, being 79, forms about 4.25 per cent. of the total deaths from this disease during this period of 11 years. Of these 79 cases, 55 , which is over 70 per cent., occurred between the ages of 10 and 19. The period of puberty seems to be without potent influence upon the production of diabetes mellitus or upon its fatal termination.

Of the 13 instances of death following the affection which occurred under 5 years of age, but 3 took place in females. Among the 66 other instances of deaths from diabetes in early life 33 ensued in males and 33 in females, exactly 50 per cent. in each sex. The external conditions of life in the United States as a general rule are in the mesin the same for both sexes to the 20 th year; a fact to which the equal.distribution of the disease in both sexes may be well ascribed.

MORTALITY FROM DIABETES MELLITUS AMONG THE COLORED POYULATION OF NEW YORK CITY, 1889-99.

In the official records I find but 15 deaths from diabetes which as designated occurred among the colored population of New York City for the past 11 years.

I could not obtain exact figures of the colored population of each year comprised in the period in question. but it seems that the death-rate from this disease in the colored race, compared with that of the white population, is exceedingly low. This may be due, to either the infrequency in which the pathologic condition appears in the Etkiopian race, or to its occasional non-recognition when it is present. The great majority of the colored people belong to the lower strata of the populace, to that class which get along with a home-made diagnosis of its ailment or frequent dispensaries or "cheap" doctors. Thus it mirht happen, that the real disease is not infrequently overlooked and that the patient treats himself or is treated for another affection.

Of the 15 specified instances, 9 dealhs occurred in males and 6 in females-a proportion divergent widely from that occurring in the white population.

56 East Seventy-sixth Street.

\section{CUTANEOUS DISEASES ACCOMPANYING DIABETES.*}

M. B. HARTZELL, M.D.

Instructor in Dermatology, University of Pennsylvania; Dermatologist to Methodist Hospital. Pitila delphia.

In this paper I shall consider those cutaneous diseases which occur with more or less frequency in diabetes, many of which are extremely annoying and painful, others dangerous, contributing in no small measure to the fatal issue of the disease. The recognition of the causal relationship existing between these eruptions and the glycosuria is an absolute prerequisite to the successful treatment of the former; and, as in many instances they are the first noticeable symptoms of diabetes, they also possess distinct value in the diagnosis

* Presented to the Section on Practice of Medicine, at the Fifty-first Annual Meeting of the American Medical Association. held at Atlantic City, N. J., June 5-8, 1900. of this affection. 'The greater number of them are of an inflammatory character, resembling in a general way the inflammatory diseases of the skin due to other causes, but also presenting certain peculiarities as to location and course, which suggest their etiology. A few are so constantly associated with sugar in the urine that they deserve the name "diabétides" first proposed by Fournier to indicate cutaneous diseases peculiar to those suffering from diabetes.

When the glycosuria is accompanied by excretion of large quantities of urine and likewise in the late stages of the malady, the skin is apt to be extremely dry, owing to the great diminution in the quantity of perspiration and sebum excreted, and a constant desquamation of fine white scales goes on; the hair too, becomes thin, dry and lusterless. This abnormal dryness of the skin is usually accompanied by a more or less marked general pruritus. The nails of the fingers and toes are likewise apt to present various abnormalities. They are unusually brittle and devoid of their normal luster; and in exceptional cases some or all of them are lost. 'This fall of the nails may be preceded by evident disease, or it may occur without precedent alteration of the nail-structure. Hemorrhage may take place into the nail-substance and trophic changes leading to deformity may occur as the secondary consequences of a liabetic neuritis. Intense pruritus localized about the rulvi in women, the scrotum in men, the perineum, anus, and inner surface of the thighs in both sexes, is an extremely common symptom of diabetes; indeed so frequent is this form of pruritus that its presence should invariably lead to an examination of the urine for sugar. 'The itching in this form of pruritus is almost unbearable and the violent scratching and rubbing to which the patient is irresistibly impelled leads in most cases to the development of an eczema.

Various forms of erythema may occur; the commonest are symmetrical patches situated on the face and a papular varıety met with usually in young subjects, consisting of split-pea-sized, pinkish, slightly elevated lesions, situated on the forearms and legs; these papules may coalesce after a time to form variously sized patches.

Urticaria of a chronic type is likewise met with in a certain proportion of cases, due either to the direct irritation of the skin by the sugar present in the circulation, or resulting from disturbances in the alimentary canal.

One of the colnmonest and most distressing cutaneous complications of diabetes is eczema, situated most frequently about the genitalia, especially in women. This may begin as a severe pruritus, no evidences of inflammation being at first visible, but presently the skin becomes inflamed, partly from the violent scratching to which the parts are subjected, partly from the irritation produced by various micro-organisms-torula cerevisiæ, etc.- whose growth is favored by the saccharine urine with which the parts are apt to be frequently soiled. In many instances the affection is eczematous from the begimning; the skin is a bright-red, and oozes a sticky serum which soon dries into thick crusts. The inflammation may be limited to the genitalia, but more commonly it spreads up over the abdomen and down over the thighs, oftentimes involving a considerable area. In many cases this eczema presents nothing peculiar except its localization; but it may assume a very acute erythematous form which runs a rapid course, a form regarded by some authors as characteristic of diabetes. In men the prepuce is often the seat of an eczematous inflammation of a very severe grade, which produces m.rked thickening and narrowing of the preputial ori- 